\title{
1 Experimental study of bending behaviour of reinforcements
}

2 E. de Bilbao - D. Soulat · G. Hivet · J.

Launay • A. Gasser

5 Received: date / Revised version: date

6 Abstract In composite reinforcement shaping, textile preform undergo biaxial ten-

7 sile deformation, in plane shear deformation, transverse compaction and out-of-plane

8 bending deformations. Up today, bending deformations are neglected in some simu-

9 lation codes but taking into account them would give more accurate simulations of forming especially for stiff and thick textiles. Bending behaviour is specific because the reinforcements are structural parts and out of plane properties cannot be directly deduced from in-plane properties, like continuous material. Because the standard tests are not adapted for stiff reinforcements with non linear behaviour a new flexometer using optical measurements has been developed to test such reinforcements. This new apparatus enables to carry out a set of cantilever tests with different histories of load. A series of tests has been performed to validate the test method and to show the capacities of the new flexometer to identify non linear non elastic behaviour.

Send offprint requests to: emmanuel.debilbao@univ-orleans.fr

Institut PRISME/MMH - University of Orléans.

Polytech'Orléans. 8 rue Leonard de Vinci, 45072 ORLEANS Cedex 2, France.

E-mail: emmanuel.debilbao@univ-orleans.fr 
Keywords Composite reinforcement - Carbon fabrics - Bending behaviour -

Experimental characterization

\section{Introduction}

21 Composite parts contain resin and can be constituted with short or long fibers [1].

22 For structural applications, long fibers and continuous reinforcements are generally

23 used which give to the piece the mechanical properties and the resin function is to re-

24 strain the motion of the yarns. Their use is increasing in automotive construction and above all in aeronautics for structural parts. Such reinforcements allow to manufacture composite structures with complex shapes for example by the RTM (Resin Transfer Molding) process. The first stage of this process consists in a shaping of the dry woven 28 preform before resin injection [2,3,4]. In prepreg draping [2] or in continuous fibre reinforcements and thermo-plastic resin (CFRTP) forming [5,6], the matrix is present but is not hardened and the deformation of the structure is driven by those of the woven reinforcement. Textile reinforcements are especially efficient in case of double curve geometries because of the interlacing of warp and weft yarns. These geometries are difficult to obtain with unidirectional reinforcements. To reach double curve geometry,

34 in-plane strains of the fabric are necessary. Because there are usually two directions of yarns (warp and weft) that are interwoven, the fabric can reach very large in-plane shear strain. variations of fiber volume fraction due to draping can have significant effect on the mold filling process $[7,8,9]$. Moreover, the orientation of reinforcement fibers within 
41 ished piece $[10,11,12]$. The prediction of the deformability of the fabric during forming,

42 by simulation tool is essential for the understanding of the manufacture process and to

43 reduce product development cycle times and cost. In order to determine the deformed

44 shape of draped fabrics, several codes have been developed based on geometrical ap-

45 proaches so called fishnet algorithms $[7,13,14,15]$. The alternative to these geometrical

46 methods consists of a mechanical analysis of the fabric deformation under the boundary

47 conditions prescribed by the forming process. This requires a model of the woven reinforcement and its mechanical behaviour, in order to compute the deformation through a numerical method, for instance, the Finite Element Method.

In one of these methods $[16,17,18,19,20]$ specific finite elements are defined that are

51 made of a discrete number of woven unit cells. The mechanical behaviour of these wo-

52 ven cells is obtained essentially by experimental analyses of the woven reinforcement.

53 Textile preforms undergo biaxial tensile deformations, in plane shear deformations,

54 transverse compaction and out-of-plane bending deformations. If all these deformations

55 can be significant in some cases it is generally possible to use a simplified approach

56 where only some strain energies are taken into account. The in plane shear strains are

57 necessary for woven reinforcement forming on a double curvature surface. The shear angles can be very large (up to $\left.50^{\circ}\right)$ while the tensile strains remain small $(1.5 \%$ for a

59 carbon fabric) [21]. In several approach bending behaviour is neglected but when the forming stage leads to the formation of defaults, like wrinkles, taking into account out

61 of plane deformation, like the bending behaviour, could make more effective these sim-

62 ulation methods [22]. Wang et al. [23] demonstrated the relative importance of bending

63 behaviour during composite forming by comparison between bending and shear ener-

64 gies in case of viscous composites.

65 Moreover, it has been shown that bending properties cannot be deduced from in-plane 
properties, like continuous material [24]. Reinforcement bending behaviour is a specific structural out of plane behaviour. It depends, among other things, on the geometrical configuration of the yarns, their mechanical properties, and the contact behaviour. The determination of the specific bending behaviour of woven reinforcement, at macroscopic 84 For experimental aspects, two standard tests are used to determine the bending stiff-

scale, is an objective of this study. This determination consists in defining a functional model. Macroscopic parameters of this model could be determined with bending tests using direct identification or inverse method. Thereby, the experimental bending test of composite reinforcements is necessary. The deformation behaviour of textiles has been studied since a long time, by experimental approaches and by development of models. Even if these studies concerning deformation of woven fabrics have been realized for the clothing industry, especially in our case for the bending, we will apply in this paper the methodology for the studied composite reinforcements.

So and since Peirce's model [25], many studies have been made to present analytical model forecasting the bending behaviour of a fabric from the yarn properties and the weave geometry in the field of clothing textiles. But these studies concern essentially plain-woven fabrics. At present, it is not possible to predict accurately the bending behaviour from only yarn properties for composite reinforcements with more complex structures such as multiplies, interlock and 3D reinforcements or non crimp fabrics. ness of fabrics: the standard cantilever test $[26,27]$ and the Kawabata bending test (KES-FB) [28]. The first is based on elastic linear behaviour and enables to determine only one parameter: the bending rigidity. However the bending behaviour is not linear elastic and the standard cantilever test is not adapted. The second test was designed by Kawabata and enables to record the moment versus the curvature during a bending cycle. Whereas it enables to show a non linear and hysteresis behaviour, it has been 
designed to test clothing textiles and is not very well adapted for composite reinforcements which are often thicker and stiffer and cannot be tested on this apparatus.

The purpose of this paper is to present a bending test for composite reinforcements with various thicknesses. In this aim, a new cantilever test using optical measurements has been designed. The sample can be either a yarn, a monoply or a multiply reinforcement which cannot be tested with standard apparatus. The bending test is performed for several overhang lengths which allow to identify non elastic behaviour. The test results are the shapes of the bent samples for the different lengths and the moment versus curvature curve. Associated to these experimental developments, we could deduce that macroscopic model for bending developed for clothing textiles are not very adapted for the composite reinforcement.

\section{Reinforcements structure and properties}

2.1 Structure and in-plane properties

As explained in the introduction, dry reinforcements studied here are composed with continuous yarns which contain thousands of fibers [29]. To allow the shaping into a non-developable shape, yarns have to be tied to one another. They can be woven, stitched or knitted. Four kinds of reinforcements have been tested in this study. All are used in aeronautical applications and enable to manufacture thick parts.

The first considered example of dry reinforcement is an $2.5 \mathrm{D}$ carbon fabric (fig. 1). Its area weight is $630 \mathrm{~g} / \mathrm{m}^{2}$ and the thickness is $1 \mathrm{~mm}$. It will be denoted "fabric A".

The second example of dry reinforcement is an interlock carbon fabric G1151® (fig. 2).

It is a laminate of four layers. Its area weight is $600 \mathrm{~g} / \mathrm{m}^{2}$, the thickness is $0.6 \mathrm{~mm}$ and it has 7.4 yarns $/ \mathrm{cm}$ in warp way and 7.4 yarns $/ \mathrm{cm}$ in weft way. It will be denoted 
114 "fabric B".

115 The third example of dry reinforcement (fig. 3) is a carbon non crimp fabric (NCF) [30].

116 It will be denoted "fabric C". It is a laminate of two unidirectional plies with yarn orientation at $\pm 45^{\circ}$ and plies tied by warp stitching. The area weight is $568 \mathrm{~g} / \mathrm{m}^{2}$ and the thickness is $1.1 \mathrm{~mm}$. In general, such reinforcement will be characterized by the number of plies, orientation of plies, dimensions of the yarns, the pattern of the stitch (chain or tricot) and its dimensions.

To increase the number of plies, it is possible to assemble several NCF reinforcements and to stitch them with another stitching yarn (fig. 4). A fourth sample has been tested. It will be denoted "fabric D". It is a multiply composed of two monoplies of the previous NCF "fabric C". Its nominal area weight is $1230 \mathrm{~g} / \mathrm{m}^{2}$.

With such structures, dry reinforcements can support high geometrical transformations under low forces because the yarns are free to move. The mechanical behaviour which results from this freedom of movement is specific and gives to the structure low rigidities compared to those of tension in yarn directions. Because warp and weft yarns are joined by weaving or stitching, the tensile behaviour is biaxial and tensile tests results have been studied in several papers [31,32]. Moreover, reinforcement forming on a double curvature shape is possible by in-plane shear strains. Thereby, in-plane shear behaviour has been thoroughly studied and corresponding tests have been developed [21].

\subsection{Bending properties}

134

Classically, bending behaviour of continuous shell is derived from the in-plane properties of the material. But $\mathrm{Yu}$ et al. [24] investigated the bending behaviour of a woven preform through a cantilever experiment and simulation where the deflection was only 

157 by Peirce [34].

due to gravity. The authors showed the discrepancy between the experimental and numerical results and concluded that bending rigidity derived from in-plane properties gives unrealistically high value compared to the experimental bending rigidity of the woven preform. During deformations, a part of the yarn will have its curvature increasing while another part will have its curvature decreasing, involving interactions between filaments and between yarns with high sliding. This multi-scale constitution gives to the reinforcement a specific bending behaviour independent of the tensile or the shear behaviour. For composite reinforcements, bending behaviour is a structural multi-scale problem which cannot be directly deduced from the in-plane material properties and it is then necessary to determine this specific behaviour. Up today, bending behaviour of reinforcement has not been the subject of many researches. On the contrary, there are a lot of studies in the field of clothing. Because of the similarity between the geometries of textiles and reinforcement, the first idea was to examine the bending behaviour of fabrics. The study of the bending behaviour of yarns or fabrics for the simulation means defining the relationship between the moment $M$ and the curvature $\kappa$ of a bent beam, plate or shell depending on the complexity of the model. Relationship between fabric behaviour, structural configuration and mechanical behaviour of yarns and their constituent fibers is complex and a critical review has been proposed by Ghosh et al. [33]. Another way is to define a macroscopic model based on rheological and experimental measurements. The simplest macroscopic model is the linear elastic (eq. 1) proposed

$$
M=B \cdot \kappa
$$


But Grosberg et al. proposed a more realistic model (eq. 2) [35] taking into account the hysteretic behaviour of the fabric with the frictional restraint couple $\mathrm{M}_{0}$ :

$$
\begin{cases}\kappa \quad=0 & \text { if } M<M_{0} \\ B \times \kappa=M-\operatorname{sign}(\kappa) \cdot M_{0} & \text { if } M \geq M_{0}\end{cases}
$$




$$
\mathrm{S}=\mathrm{G} / \mathrm{w}
$$

$\mathrm{S}=\frac{1^{3}}{8} \cdot \frac{\cos \theta / 2}{\tan \theta}$

The cubic root of $\mathrm{S}$ allows to compare the fabrics. It has the unit of a length and is called by Peirce "the bending length". Today, the standard commercial apparatus are defined with a specific value equal to $41.5^{\circ}$ for the angle of the tilted plane. With this value, the equation (5) becomes simpler:

$\approx 1^{3} / 8$

This configuration is described in standard tests [26,27].

On this principle, Grosberg [35,38] proposed a cantilever test to determine the both parameters of his model (eq. 2). Considering two specific values of $\theta\left(\theta=40^{\circ}\right.$ and $\left.\theta=20^{\circ}\right)$ and assuming the load as a concentrated and a distributed load, the parameters are computed using functions derived from known solutions.

Lastly, Clapp et al. [39] developed an indirect method of experimental measurement of the moment-curvature relationship for fabrics based on recording the coordinates of the deformed sample. Applying least square polynomial regression and numerical differentiation techniques, moment-curvature relationship is computed from coordinate data and weight per unit width. This method allows taking into account the non linear behaviour but assumes elastic behaviour. 
Kawabata's Evaluation System was originally designed to measure basic mechanical properties of fabrics [28]. It became a set of standard tests for tensile, shear, compression, surface roughness and bending behaviour. KES-FB tester (fig. 6) is the test to quantify properties in pure bending deformation mode and enables then to record directly the evolution of the bending momentum per unit width versus the curvature during a load unload cycle.

The dimension of the sample in the bending direction is equal to $1 \mathrm{~cm}$ and its width is $20 \mathrm{~cm}$ for flexible fabrics. It is clamped between a fixed (A) and a moving (B) clamps (fig. 6). The fixture setting of the sample in the clamps ensures pure bending deformation. During the test, the moving clamp (B) rotates round the fixed one (A) ensuring a constant curvature through the sample length. The movement is made with a constant rate of curvature equal to $0.5 \mathrm{~cm}^{-1} \mathrm{~s}^{-1}$ from $-2.5 \mathrm{~cm}^{-1}$ to $2.5 \mathrm{~cm}^{-1}$. As indicated in the manual of the apparatus, the bending rigidity $\mathrm{B}$ and the bending hysteresis $\mathrm{M}_{0}$ of Grosberg's model are computed as follow: the slopes are computed respectively between $\kappa=0.5 \mathrm{~cm}^{-1}$ and $\kappa=1.5 \mathrm{~cm}^{-1}$ for $\mathrm{s}_{1}$ and between $\kappa=-0.5 \mathrm{~cm}^{-1}$ and $\kappa=-1.5 \mathrm{~cm}^{-1}$ for $\mathrm{s}_{2}$ (see eq. 7 ).

$\left\{\begin{array}{l}s_{1}=\frac{\Delta M=M(\kappa=1.5)-M(\kappa=0.5)}{\Delta \kappa=1} \\ s_{2}=\frac{\Delta M=M(\kappa=-0.5)-M(\kappa=-1.5)}{\Delta \kappa=1} \\ B=\left(s_{1}+s_{2}\right) / 2\end{array}\right.$

The bending hysteresis, that is the frictional restraint force $M_{0}$, is the half average of the two hysteresis values $h_{1}$ and $h_{2}$ computed respectively at $\kappa=1 \mathrm{~cm}^{-1}$ and 
214

$\kappa=-1 \mathrm{~cm}^{-1}$ (see eq. 8 ).

$\left\{\begin{array}{l}h_{1} \quad=M_{l}(\kappa=1)-M_{u l}(\kappa=1) \\ h_{2} \quad=M_{l}(\kappa=-1)-M_{u l}(\kappa=-1) \\ 2 \cdot M_{0}=\left(h_{1}+h_{2}\right) / 2\end{array}\right.$ is in $\mathrm{cm}^{-1}$. the thickness.

\section{New flexometer}

\subsection{General description} to test different reinforcements.

where $\mathrm{M}_{l}$ and $\mathrm{M}_{u l}$ are respectively the moment for load and unload curve.

Figure 7 presents the results of the KES-FB test carried out on fabric A in weft direction. The Grosberg's curve is drawn on the figure and the parameters are presented in table 1 . In this example, bending moment is in $\mathrm{gf.cm} / \mathrm{cm}(1 \mathrm{gf} \simeq 1 \mathrm{cN})$ and curvature

This experimental bending test was developed for flexible textiles and testing stiff or thick reinforcements requires to reduce length of the sample. Finally, it is neither possible to test stiffer multiply reinforcements nor to easily observe the behaviour in

Within standard testers (cantilever, KES-FB and other less known ones) cantilever principle has been retained for a new flexometer because of its simplicity and flexibility

This new flexometer is constituted by two modules: a mechanical module and an optical module. The mechanical module enables to place the sample in cantilever configuration under its own weight. It is also possible to add a mass at the free edge of the sample to reach larger curvatures. The optical module takes pictures the shape of the bent sample. The sample can be a yarn, a monoply or multiply reinforcement. It has a 
234 length about $300 \mathrm{~mm}$ and a width up to $150 \mathrm{~mm}$. The thickness can reach several

235 millimeters.

236 At the beginning of the test (fig. 8(a)), the sample (S) is placed upon a fixed board (F)

${ }_{237}$ and a special plane comprising laths (B). The length direction of the sample must be 238 parallel to the bending direction and its free edge must be aligned with the lath (L1). A translucent plate $(\mathrm{C})$ is fixed upon the both to ensure the embedding condition. Thus the sample (S) will not slide. During the test, because of the translation of the drawer $(\mathrm{T})$, the laths will successively retract, beginning with lath (L1), and the length of overhang will increase. The test is stopped for a chosen overhang length $\mathrm{L}$ and is continued for new lengths. Thus, the complete test is a succession of quasistatic tests with different loading cases. While single cantilever test provided only one configuration, the new flexometer, with its set of loading cases associated with the different bent shapes, enables to identify a non elastic behaviour model.

Like in several studies of textile deformability during composite processing [40] full-field strain measurements are applied to measure the deformed shape of the bent sample. A digital camera takes a picture for each length and the images are processed to extract the shapes of the bent sample (fig. 8(b)). A previous step of pixel calibration [41] is required so that pixel measurements can be translated into real dimension by scaling. Then, the image of the bent sample profile is captured, filtered [42], and binarized. The following step is to extract the borders of the binary object and to deduce the mean 


$$
\begin{aligned}
\kappa & =\frac{z^{\prime \prime}}{\left(1+z^{\prime 2}\right)^{3 / 2}} \\
L_{b} & =\int_{x_{E}}^{x_{F}} \sqrt{1+z^{\prime 2}} \mathrm{~d} t \\
s(P) & =\int_{x_{E}}^{x_{P}} \sqrt{1+z^{\prime 2}} \mathrm{~d} u \\
M(s) & =W \int_{s}^{L_{b}}(u-s) \cos (\varphi) \mathrm{d} u
\end{aligned}
$$

4.2 Post processing

At the end of the experimental test, a set of bent shapes is provided. Each bent shape is defined by the bending length at which the deformed shapes has been obtained and by the data points defined in a coordinate system. The subsequent post-processing of the profiles aims to deduce from them the evolution of the moment with the curvature. Each shape of the bent sample, defined by a set of data points, is smoothed by a series of exponential functions plus a first order polynomial to ensure the boundary conditions at embedded point. For each length of bending test, bending moment and the curvature have to be computed along the profile and moment-curvature graph can be drawn.

Assuming the sample as a shell with its length $\mathrm{L}_{0}=\mathrm{L}$ in initial configuration, the new length is noted $\mathrm{L}_{b}$ in bent configuration. The total strain energy $\mathrm{U}_{t}$ is the summation of the bending energy $\mathrm{U}_{b}$, the membrane strain energy $\mathrm{U}_{m}$, and the transverse shear energy $\mathrm{U}_{T S}$. In this case, assuming that the bending moment $\mathrm{M}(\mathrm{s})$, the axial stress $\mathrm{N}(\mathrm{s})$ and the transverse shear $\mathrm{T}(\mathrm{s})$ are the only non zero stress components and that they depend only on the curvilinear abscissa s (see fig. 10) along the profile:

$\mathrm{P}$ defined by the curvilinear abscissa $\mathrm{s}=\mathrm{s}(\mathrm{P})$ is the point where the bending moment $\mathrm{M}(\mathrm{s})$ applied by the part PF and the curvature kappa are computed. W is the weight per unit length $(\mathrm{N} / \mathrm{m})$. $\mathrm{u}$ and $\varphi$ are the Frenet's coordinates of the point $\mathrm{Q}$ moving 
along the shape from $\mathrm{P}$ to $\mathrm{F}$.

$$
\left\{\begin{array}{l}
U_{t}=U_{b}+U_{m}+U_{T S} \\
\left.U_{t}=\int_{0}^{L_{b}} M(s) \cdot \kappa(s) \mathrm{d} s+\int_{0}^{L_{b}} N(s) \cdot \varepsilon_{s}(s) \mathrm{d} s+\int_{0}^{L_{b}} T(s) \cdot \gamma(s)\right] \mathrm{d} s
\end{array}\right.
$$

Assuming that we are in pure bending deformation the membrane strain energy is insignificant by comparison with the bending energy, it follows that membrane strains are negligible and that bent length $\mathrm{L}_{b}$ is equal to initial length $\mathrm{L}$. Finite element simulation of this bending test has been developed, in good agreement on the bending deflection value and confirms this hypothesis that membrane strains are negligible [43].

$U_{b}=\int_{0}^{L} M(s) \cdot \kappa(s) \mathrm{d} s$

$L_{b}=L$

\subsection{Test interpretation}

Three curves are deduced of the experimental test (fig. 11):

- M(L) (fig. 11(a)): each curve presents the evolution of the bending moment applied at a material point with the bending length.

$-\kappa(\mathrm{L})$ (fig. 11(b)): each curve presents the evolution of the curvature of the shape at a material point with the bending length.

$-\mathrm{M}(\kappa)$ (fig. 11(c)): this curve is obtained by combination of the both previous.It presents the evolution of the moment with the curvature as the actual behaviour of the material.

Two points of the shape, $\mathrm{P}$ and $\mathrm{Q}$ are followed to illustrate the interpretation. During the test, points which are before the embedded point have a zero bending moment and a zero curvature: before $\mathrm{L}_{P}$ for $\mathrm{P}$ and before $\mathrm{L}_{Q}$ for $\mathrm{Q}$. With increasing length of overhang, when a point becomes the embedded point $\left(\mathrm{L}=\mathrm{L}_{P}\right.$ for $\left.\mathrm{P}\right)$, its moment becomes 
equal to the resultant bending moment due to the bent part of the sample. Length of overhang continues to increase and this point has its bending moment decreasing because of the increasing inclination of the bent part.

Thus, when $\mathrm{Q}$ becomes the embedded point $\left(\mathrm{L}=\mathrm{L}_{Q}\right)$, moment has already decreased for point $\mathrm{P}$. For each material point, its moment reaches maximum value when it becomes the embedded point and decreases after. Assuming an increasing relationship between moment and curvature, which seems to be realistic, the curvature reaches also its maximum value at the embedded point and decreases after (see curve $\kappa(\mathrm{L})$ ).

If the material has an elastic behaviour, load and unload curves of the momentcurvature graph are superposed (curve $\mathrm{m}(\kappa)$ ). In this case $\mathrm{P}$ and $\mathrm{Q}$ go up and down along the elastic curve (continuous line). Thus, only one length of overhang, that is only one bent shape, will be sufficient [39].

For non elastic and nonlinear behaviour (fig. 11) the locus of the points which have the moment and curvature at their maximum values (at the embedded point) gives the load part of moment-curvature curve (continuous line). On the other hand, following the moment and the curvature for a material point will give the unload curve (dash line). It is then necessary to test the bending behaviour with several lengths of overhang.

This explanation points out the difference between the new flexometer with its complete test and the simple standard cantilever test. The standard test enables to provide only bending rigidity for linear elastic model if only one point of the shape is exploited. It enables to provide the parameters of a non linear but elastic model if the complete shape is processed. But it does not enable to provide parameters for non elastic model contrary to the new flexometer which takes into account the history of the deformations and enables then to identify non elastic models.

Moreover, each point has its maximum value of bending moment when it is the em- 
bedded point (E). From equations (12) and (15), it follows that this value depends on

$319 \mathrm{~L}$

$\mathrm{M}(\mathrm{E})=\mathrm{W} \int_{0}^{\mathrm{L}} s \cos (\varphi) \mathrm{d} s$

Each point undergoes a load at a maximum value increasing with the bending length and an unload. During the unload phase, the behaviour could be different in function of the level of load and in function of the material behaviour. For example, the behaviour of the sample can be quasi elastic for low bending length (low curvature), and can become strongly hysteretic with high bending length (high curvature). The new flexometer test is then equivalent to a set of KES-FB tests with different ranges of curvature.

In practice, after having deduced moment-curvature curve for each bending length, we'll see if the curves are superposed. In this case we consider that the behaviour is elastic $^{1}$ and the moment-curvature graph for the greatest length enables to define the bending model. If not, the moment and the curvature computed at embedded point for each length of bending test enable to plot a point on the moment-curvature load graph as explained above.

\section{Bending tests}

5.1 Test on fabric A and validation of flexometer

A test has been performed on fabric A (sec. 2.1) on the new flexometer presented in section 4 and compared with measurements performed on KES-FB (Kawabata Evaluation System) at ENSISA (Ecole Nationale Supérieure d'Ingénieurs Sud Alsace) of

\footnotetext{
1 but non necessarily linear
} 
Mulhouse.

For the flexometer, the sample's width is equal to $100 \mathrm{~mm}$ and the test has been performed with the bent strip under its own weight only. The weft direction of the sample was parallel to the bending direction of the flexometer. The usable bending length varied from $100 \mathrm{~mm}$ to $210 \mathrm{~mm}$. The first step within the results analysis is to verify if the behaviour is linear elastic. For each bent shape, the angle $\theta$ of the chord with the horizontal axis defined by Peirce's test has been determined (fig.5). It follows the flexural rigidity $\mathrm{G}$ according to equations (4) and (5). If the behaviour is linear elastic, this parameter should be constant. Figure 12 shows the evolution of this parameter with the bending length $\mathrm{L}$. It turns out that $\mathrm{G}$ decreases while the length increases. With a variation of about $42 \%$ (tab. 2), it can be inferred that the behaviour is not linear $^{2}$ for the fabric considered.

Figure 13 shows the evolution of the moment with the curvature computed along the profile for three lengths $\mathrm{L}=100 \mathrm{~mm}, \mathrm{~L}=150 \mathrm{~mm}$ and $\mathrm{L}=210 \mathrm{~mm}$. Moment is in $\mathrm{N}$ (moment per unit width). Other lengths have been tested but they are not plotted for more clarity. It can be observed inflexions for low curvatures which don't represent physical reality but are due to wiggles of the smoothing function in quasi rectilinear parts of the profiles. It ensues that the curve given for $\mathrm{L}=100 \mathrm{~mm}$ may be not usable. The curves seem to be superposed which could indicate a quasi-elastic behaviour. In this case, the bending behaviour is described by the moment-curvature curve given for the largest length as explained in section 4.3.

For each bending length, let curvature and moment computed at the embedded point be considered. Curvature increases with the length increasing but changes very slowly for length greater than $200 \mathrm{~mm}$ due to the low moment arm. For the largest length

\footnotetext{
2 but it can be elastic nevertheless
} 
it is around $0.045 \mathrm{~mm}^{-1}$ (fig. 14(a)). Concerning the maximum moment, it can be noticed a little inflexion because of the decreasing moment arm and the softening of the structure (fig. 14(b)). The combination of these both curves allows deducing the loading curve. In the case of elastic behaviour, loading curve is superposed with moment-curvature curve computed along the profile.

For the KES-FB bending test carried out on fabric A, the sample width has been reduced to $3 \mathrm{~cm}$ instead of $20 \mathrm{~cm}$ to complete the test. Figure 7 shows the momentcurvature graph recorded for a test performed on one of the samples. Figure 15 shows the moment-curvature curve recorded during the test KES-FB and with the flexometer. It can be noted that flexometer measurements are in good agreement with KES-FB bending test. Due to the limitation on the KES system, it has been impossible to carry out a complete test with another composite reinforcements (like two plies of fabric A, nor with two plies of fabric C). We can conclude, as even, by these comparisons with the KES-FB test, that in our experimental methodology, the flexometer test is validate.

\subsection{Test with larger curvature}

The second set of tests has been performed on fabric B (sec. 2.1). A first series of five tests has been performed under their own weights only and in weft direction. The samples width was equal to $100 \mathrm{~mm}$ and the usable bending length varied from $100 \mathrm{~mm}$ to $260 \mathrm{~mm}$. Figure 16 show the repeatability of the deflection of the samples for three lengths. The relative standard deviation of the maximal deflection undergoes a variation by $1 \%$ for larger length to $19 \%$ for smaller length. Another test of intrinsic repeatability of the flexometer gave a relative standard deviation of the maximal deflection less than $0.2 \%$ for large lengths and $5 \%$ for small lengths. It follows that the 
observed repeatability is essentially due to the material scattering.

The Peirce's rigidity variation shows again that the behaviour is not linear elastic (tab. 3). Concerning the curvature (fig. 17(a)), it increases with the length increasing with a more marked visible asymptotic behaviour. For the largest length it reaches around $0.036 \mathrm{~mm}^{-1}$. For the moment (fig. 17(b)), a change of slope can be observed around $\mathrm{L}=190 \mathrm{~mm}$. To complete the repeatability of the test, a study of the scatterings of curvature indicated that the relative standard deviation is length independent and comprised between 5 and $21 \%$. These large variations are due still to the numerical double derivative of the smoothing exponential function (with wiggles) to compute the curvature (sec. 4.2). In opposite, the relative standard deviation of moment, between 1 and $5 \%$, is much less extensive because moment is computed by integration.

A metal strip has been stuck on the free edge of the sample to reach larger curvatures in the second series of tests. This added mass increases the moment especially at the beginning of the test for small bending lengths. Consequently the deformation of the sample is accelerated. Test have been performed with strip which had the weight equal to the two third of the sample weight. This time, the bending length varied from $50 \mathrm{~mm}$ to $240 \mathrm{~mm}$. Figure 18 presents the moment versus the curvature computed along the profiles for all the lengths for one of the samples. Using the mass, the maximum curvature can reaches the significant value of $0.15 \mathrm{~mm}^{-1}$. It's an advantage of our experimental system, with the possibility to add a mass in fact to reach large value of the curvature, without changing the sample geometry. Moreover, it can be noted larger range of curvature. The curves are divided into two sets. The curves of the first set are superposed which indicates an elastic behaviour. In opposite, the curves split off in the second set. The behaviour is non elastic. The behaviour changes for $\kappa$ between 
0.04 and $0.045 \mathrm{~mm}^{-1}$.

Finally, figure 19 shows the averages of the loading curves (e.g. moment and curvature computed at embedded point) for the two sets of tests (under own weight only and with added mass) performed on fabric B. For the tests carried out under own weight only, the curvature reaches $0.036 \mathrm{~mm}^{-1}$ and the moment $0.11 \mathrm{~N}$. The behaviour is only elastic all over the range of curvature. For the tests carried out with added mass, the curvature reaches $0.10 \mathrm{~mm}^{-1}$ and the moment $0.12 \mathrm{~N}$. The marked change of slope confirms that the material change from an elastic behaviour to an inelastic at curvature between 0.04 and $0.045 \mathrm{~mm}^{-1}$. It can be observed a good continuity between the two series (without and with added mass). 5.3 Non Crimped Fabric bending test Another test has been performed on a fabric C (Non Crimp Fabric) presented in section 2.1. The sample had its width equal to $50 \mathrm{~mm}$. The test has been performed with the bent strip under its own weight only. The results are presented for bending lengths between $100 \mathrm{~mm}$ and $170 \mathrm{~mm}$. Because moment-curvature computed along the profiles indicated a non elastic behaviour, bending moment and curvature have been computed at the embedding point. These results are directly presented in the figure 20. From low curvatures, points seem to be in an asymptotic zone and the moment increases very little. The non woven structure should enable the fibers and the yarns to slide widely. Because the behaviour seems to be inelastic from the low curvatures and assuming an hysteretic behaviour, Dahl's model [44] can be chose to fit with the moment-curvature curve using least square method. This model is used by Ngo Ngoc et al. to fit on KES bending tests performed on clothing textiles [36]. It is very efficient for clothing tex- 
433 tiles and it could be a good starting point for reinforcements. The bending curve is

${ }^{434}$ defined by a differential equation where moment is only curvature dependent and rate

435 independent:

$\frac{d M}{d \kappa}=B_{0}\left(1-\frac{M}{M_{0}} \operatorname{sign}(\stackrel{\circ}{\kappa})\right)$

436 The optimization of Dahl's model gives $\mathrm{B}_{0}=6.11 \mathrm{~N} \cdot \mathrm{mm}$ and $\mathrm{M}_{0}=0.040 \mathrm{~N}$.

${ }^{437}$ A second test has been performed on fabric D (2 stitched multiplies of fabric C). The

438 sample's width is $100 \mathrm{~mm}$. The test has been performed with the bent strip under its

439 own weight only. The results are presented for bending length between $100 \mathrm{~mm}$ and

$440170 \mathrm{~mm}$. Bending moment and curvature have been computed at the embedding point

441 and reported on the figure 20 . This time, first points seem to be in an increasing zone

442 while last points seem to have reached asymptotic zone. Assuming again an hysteretic

443 behaviour, the Dahl's model has been chosen to fit with the experimental curve and

444 the optimization gives $\mathrm{B}_{0}=8.92 \mathrm{~N} . \mathrm{mm}$ and $\mathrm{M}_{0}=0.104 \mathrm{~N}$. With two plies, the initial

445 bending rigidity $\mathrm{B}_{0}$ increases by $45 \%$ and the asymptotic momentum $\mathrm{M}_{0}$ increases

${ }_{446}$ by $160 \%$. In the case of elastic linear shell hypothesis without in-plane shear strain,

447 the bending rigidity should have increased by cubic variation of thickness. If both

448 of the plies were free to slide completely, the bending rigidity would be near to the

449 value of one ply. Because of the warp stitch, the plies are not completely free to slide and the bending behaviour of the multiply results of the bending behaviour of the structural monoply plus frictional interactions between the two plies and action of the stitch. However, again because of the difficulty to compute the curvature, data points are scattered and the question arises as to whether Dahl's model is suitable for the reinforcement considered. 
Bending behaviour of composite reinforcements is going to become a significant behaviour to take into account in forming processes simulations, especially in case of the simulation of out-of-plane phenomenon during these processes, like the wrinkles. This behaviour is a specific complex multi-scale mechanical problem. At macroscopic scale bending behaviour is described by the constitutive moment curvature relationship which is not linear and depends on the range of the curvature. Whatever the scale used to approach the problem, a macroscopic bending test is warranted to verify the model and identify experimentally the behaviour. Present standard bending tests designed for clothing textiles are not adequate for composite reinforcements. Thereby, a new cantilever test has been designed to test various reinforcements with different thicknesses, different woven structures and with low or large bending rigidity. In the new flexometer test, optical measure and image processing accurately provide cartesian coordinates of the deformed sample for each bending length. From these, a first direct method enables to plot the moment-curvature graph. Contrary to the classical cantilever test, the flexometer test is operated with several bending lengths which allows obtaining non linear non elastic bending behaviour because the test takes into account the history of the deformation. Moreover, a complete flexometer test is equivalent to multiple KES-FB tests with different ranges of curvature because KES-FB tests only one point with only one history while the new flexometer tests a set of points with different histories of load.

A first test performed on the same kind of reinforcement both with new flexometer and KES-FB tester allowed to validate the new test method. The second set of tests showed that the repeatability of the position of the shape ensued from natural repeatability of 
the material but it pointed out also the extensive uncertainties of curvature because of the numerical double derivative computation. This highlights the limit of the direct method. A set of tests with an added strip stuck to the free edge allowed to access to larger curvature and to identify the change from elastic to non elastic behaviour. Finally tests performed on monoply and multiply allowed to compare their bending properties. These last tests have shown that the flexometer enables to test thicker and stiffer reinforcements than KES-FB apparatus.

Associated to this experimental development this study permits us to show the limits of the bending models developed for clothing textile, when they are used for composite reinforcement. The loads are significantly higher in composite materials applications than in the clothing industry, the constitution and the rigidity are different and consequently models for deformation of woven fabrics as developed for the clothing industry are often not applicable for composites [45]. The definition of a specific model concerns ours futures works for the bending behaviour. This definition will be associated to an inverse method built on experimental results and results obtained by the simulation of the bending test by finite element method. The aim of inverse method is to optimize the parameters of the chosen model, by minimizing the gap between experimental shape and simulated shape.

Acknowledgements The authors thank Laurence Schacher of the Laboratoire de Physique et Mécanique Textiles de Mulhouse ( ENSISA) to have allowed us to perform the KES bending tests. The authors acknowledge also the support of the ITOOL European project.SIntegrated Tool for Simulation of Textile Compositeš̌, European Specific Targeted, Research Project, SIXTH FRAMEWORK PROGRAMME, Aeronautics and Space, http://www.itool.eu. 
Table 1 Grosberg's parameters computed on KES-FB test carried out on fabric A

\begin{tabular}{|l|l|l|}
\hline$s_{1}(\mathrm{gf.cm})$ & $s_{2}(\mathrm{gf.cm})$ & $B(\mathrm{gf} . \mathrm{cm})$ \\
\hline 3.95 & 3.40 & 3.68 \\
\hline$h_{1}(\mathrm{gf})$ & $h_{2}(\mathrm{gf})$ & $M_{0}(\mathrm{gf})$ \\
\hline 6.44 & 5.04 & 2.87 \\
\hline
\end{tabular}

Table 2 Flexometer test on fabric A. Variation of flexural rigidity G with bending length L.

\begin{tabular}{|c|c|c|c|}
\hline$G_{\min }$ & $G_{\max }$ & $G_{\operatorname{moy}}$ & $\Delta G=\frac{G_{\max }-G_{\min }}{G_{\operatorname{moy}}}(\%)$ \\
\hline 4,49 & 6,78 & 5,42 & 42,3 \\
\hline \multicolumn{3}{|c|}{$(\mathrm{N} . \mathrm{mm})$} & $(\%)$ \\
\hline
\end{tabular}

Table 3 Flexometer test on fabric B. Variation of flexural rigidity G with bending length L.

\begin{tabular}{|c|c|c|c|}
\hline$G_{\min }$ & $G_{\max }$ & $G_{\operatorname{moy}}$ & $\Delta G=\frac{G_{\max }-G_{\min }}{G_{\operatorname{moy}}}(\%)$ \\
\hline 6,16 & 11,07 & 8,84 & 55,6 \\
\hline \multicolumn{3}{|c|}{$(\mathrm{N} . \mathrm{mm})$} & $(\%)$ \\
\hline
\end{tabular}




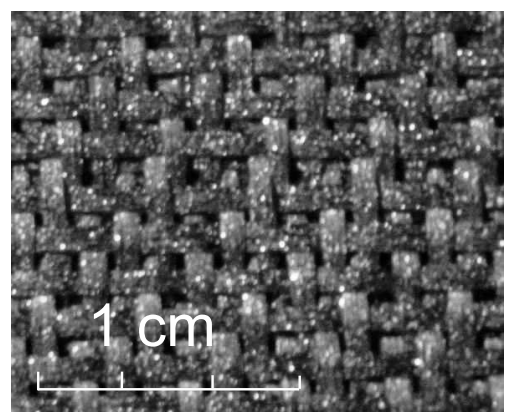

Fig. 1 Fabric $\mathrm{A}=2.5 \mathrm{D}$ carbon fabric

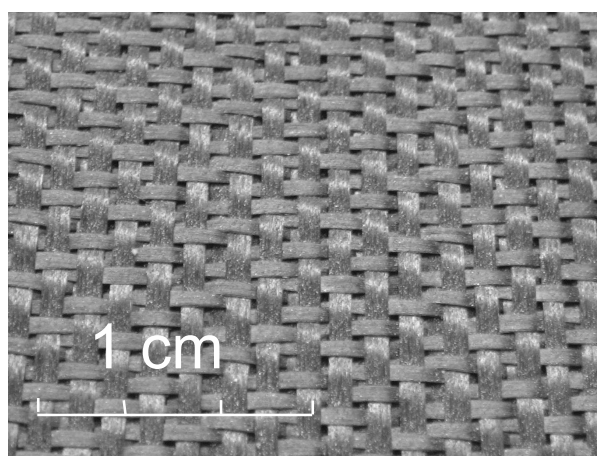

Fig. 2 Fabric B = interlock carbon fabric, G1151®

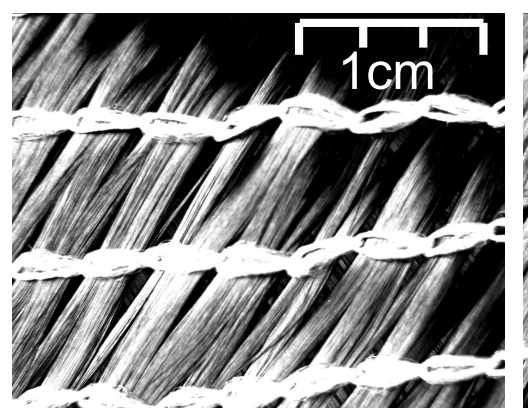

(a) Top

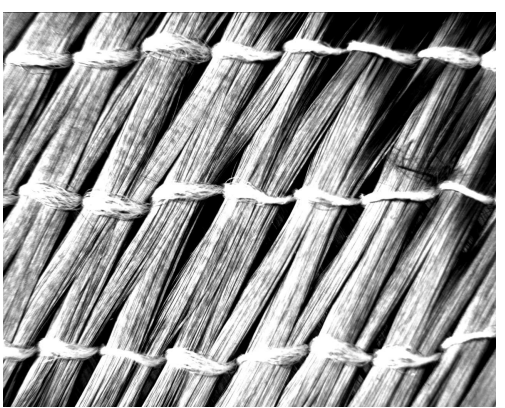

(b) Bottom

Fig. 3 Fabric $\mathrm{C}=$ carbon Non Crimp Fabric $(\mathrm{NCF})$ 


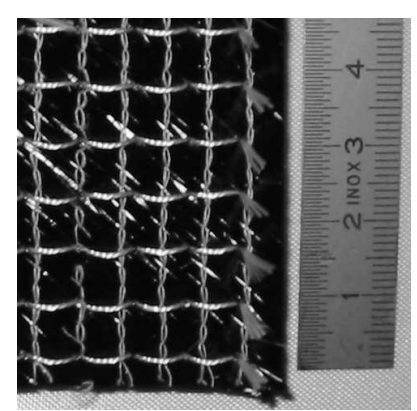

(a) Top

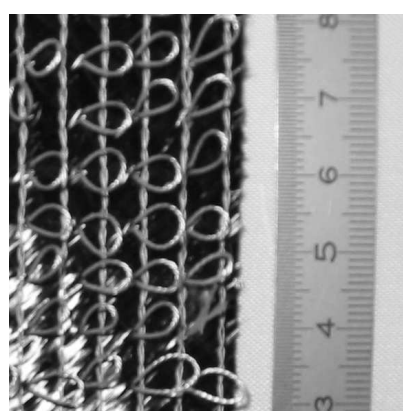

(b) Bottom

Fig. 4 Fabric D = Multiply Non Crimp Fabric (2 plies of fabric C) 


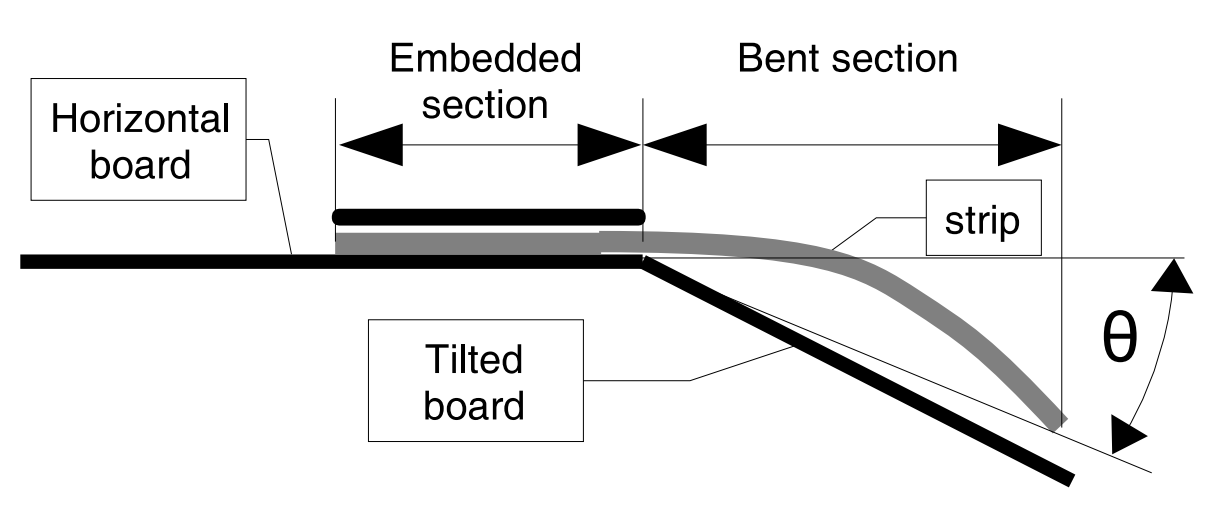

Fig. 5 The cantilever test for fabric: The Peirce's test is without the tilted board and the length of overhang is constant and $\theta$ is variable. With the standard cantilever test, the sample slides until it touches the tilted board at $\theta=41.5^{\circ}$. The length of overhang is variable and $\theta$ is constant. 


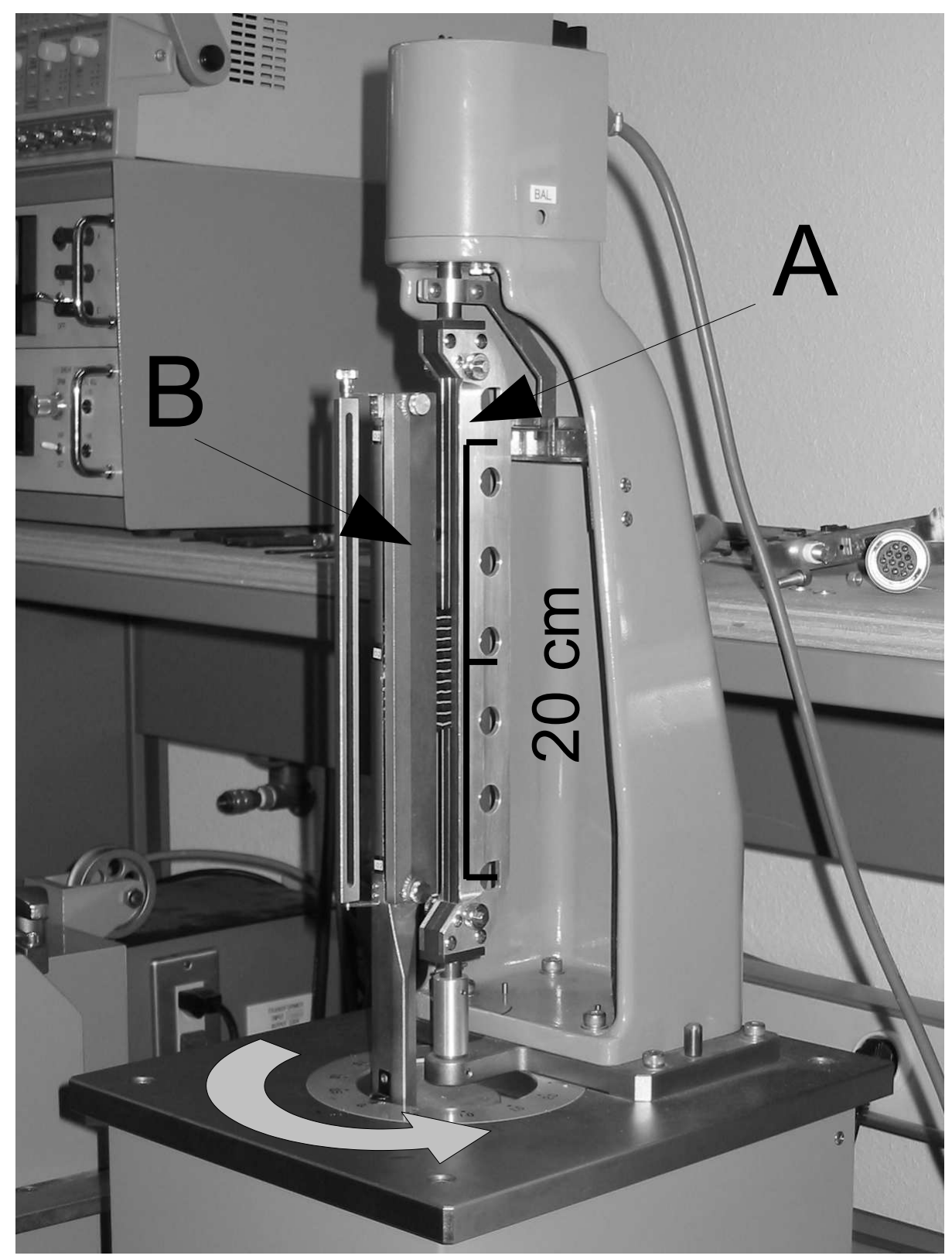

Fig. 6 Kawabata bending test - KES-FB2 / ENSISA Mulhouse 


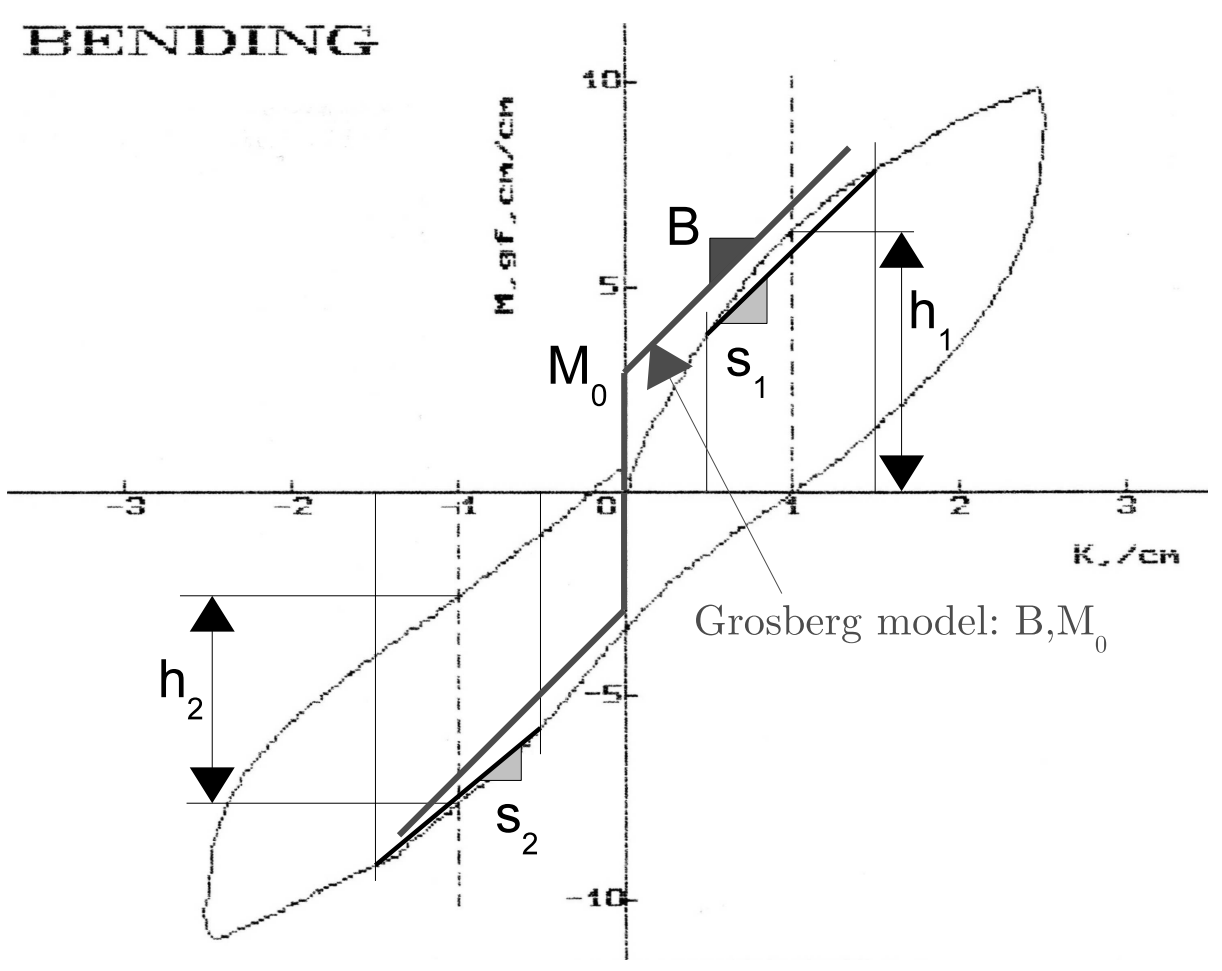

Fig. 7 KES FB2 test data carried out on fabric A and Grosberg's parameters 


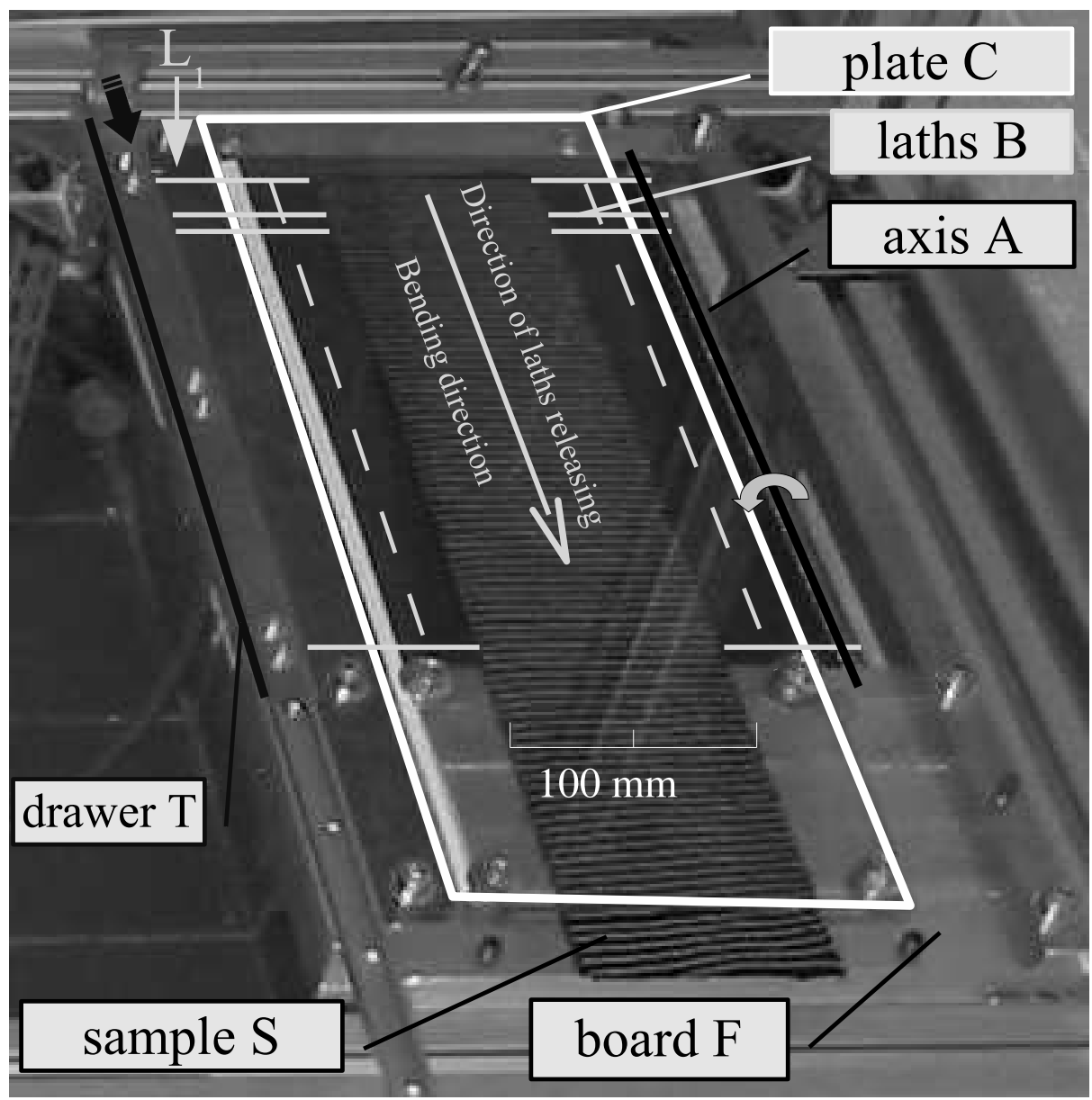

(a) Flexometer - Mechanical module with sample

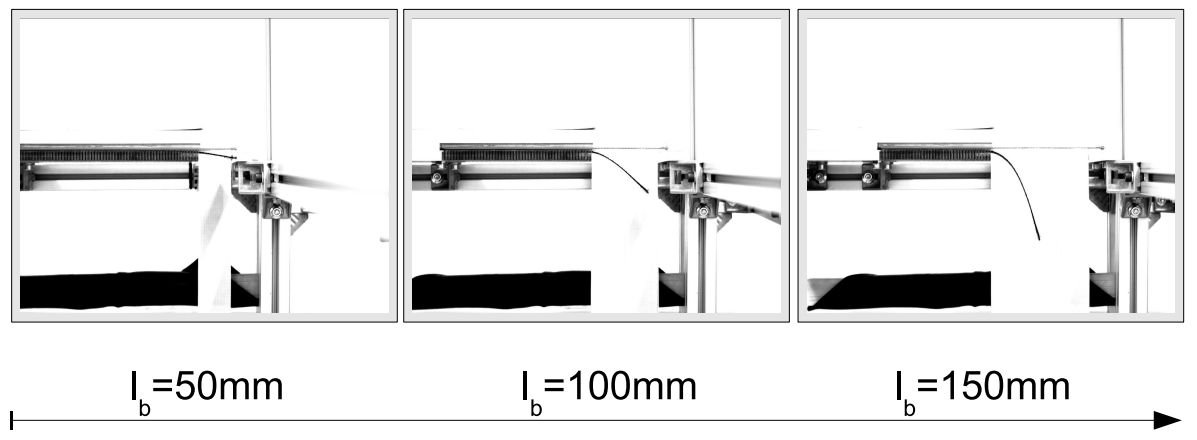

(b) Three successive bending lengths measurements during a test. Pictures taken by optical module

Fig. 8 New flexometer based on cantilever test with successive bending lengths 


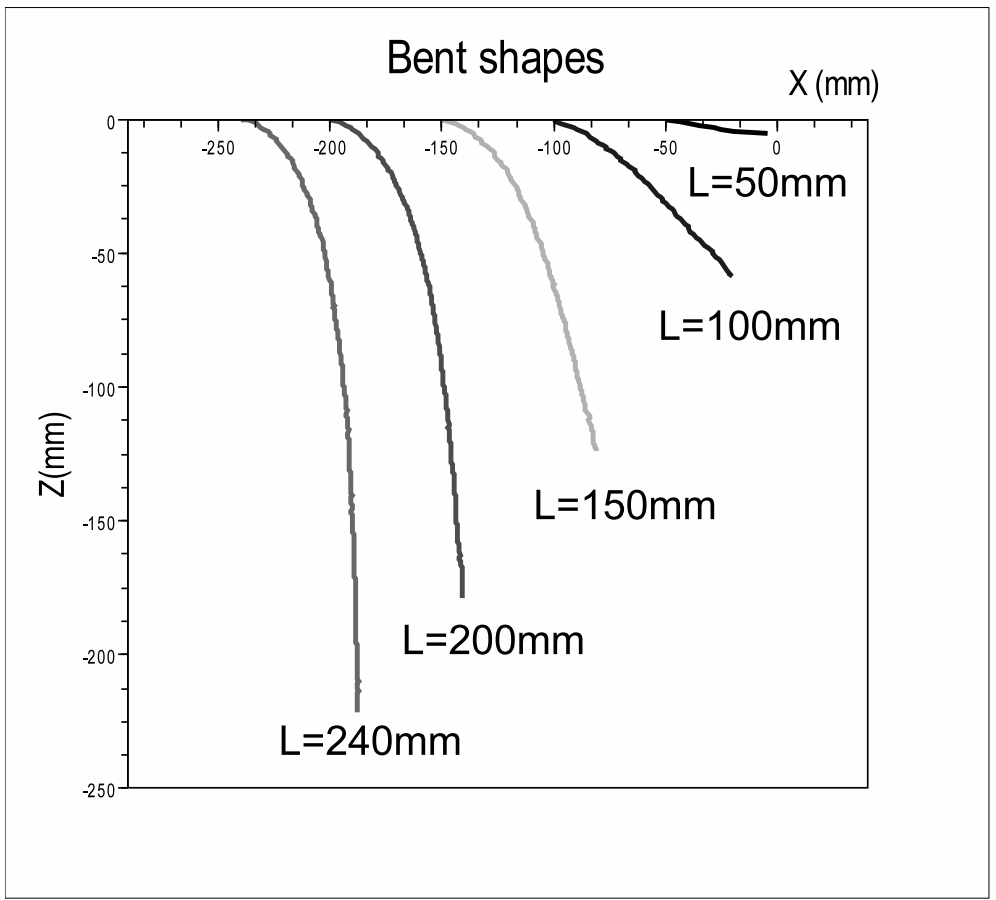

Fig. 9 Flexometer test - For each bending length, a profile is extracted from the picture by image processing.

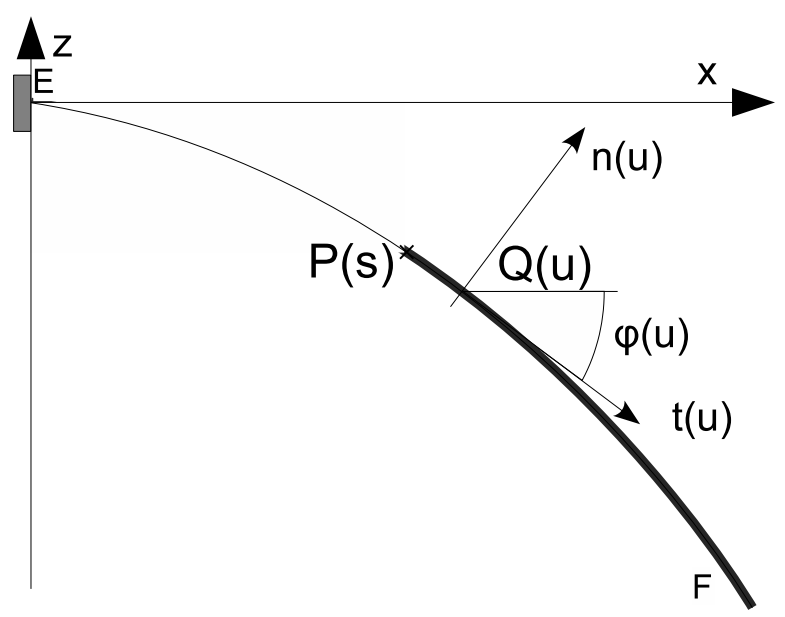

Fig. 10 Bending moment computing along the profile. $\mathrm{E}$ is the embedded point. F corresponds to the free edge. Curvature and moment are computed at general point $\mathrm{P}$ with curvilinear abscissa s 


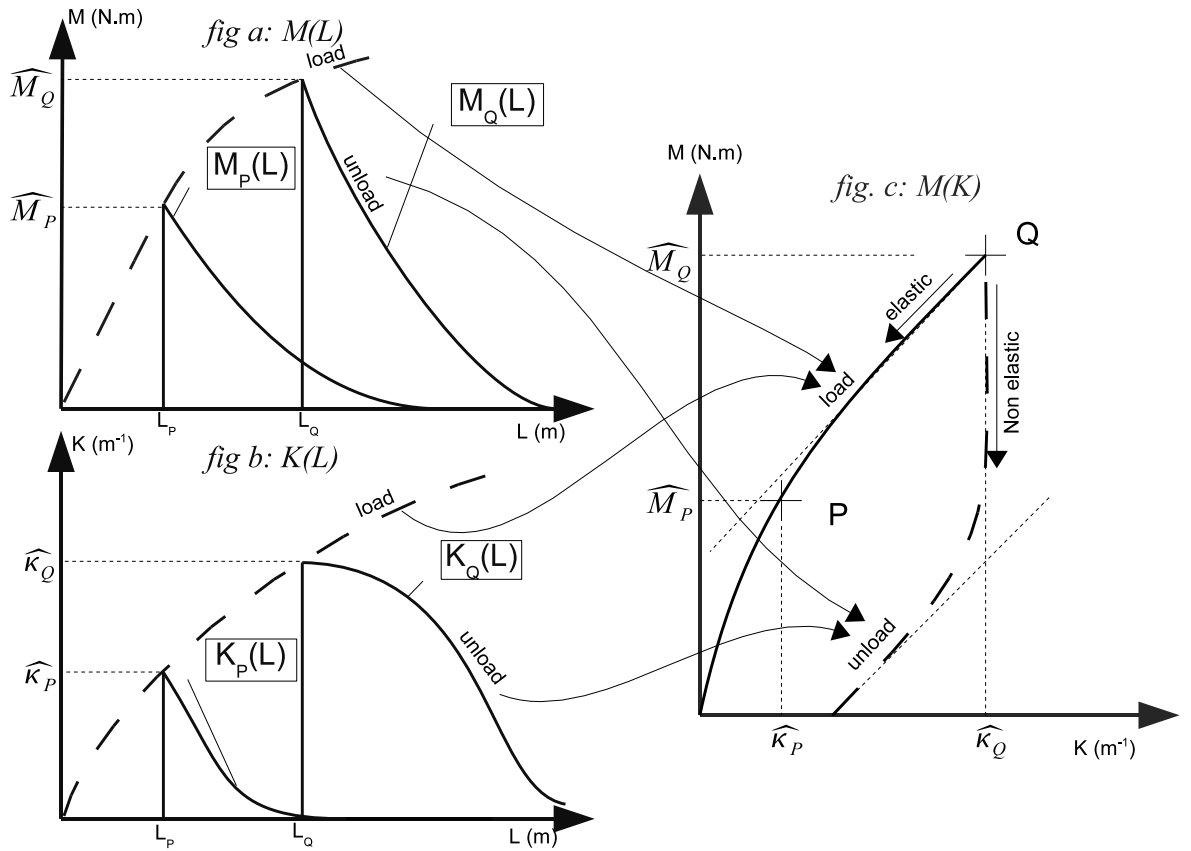

Fig. 11 Flexometer - Test interpretation. Elastic and non elastic behaviour 


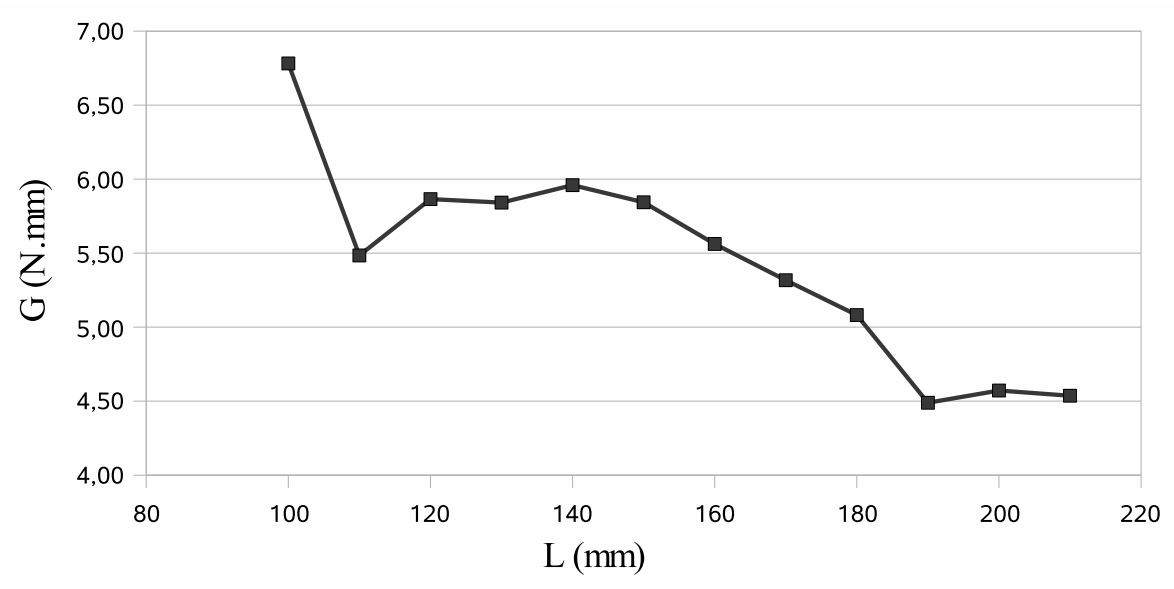

Fig. 12 Flexometer test on fabric A. Evolution of flexural rigidity G with bending length L.

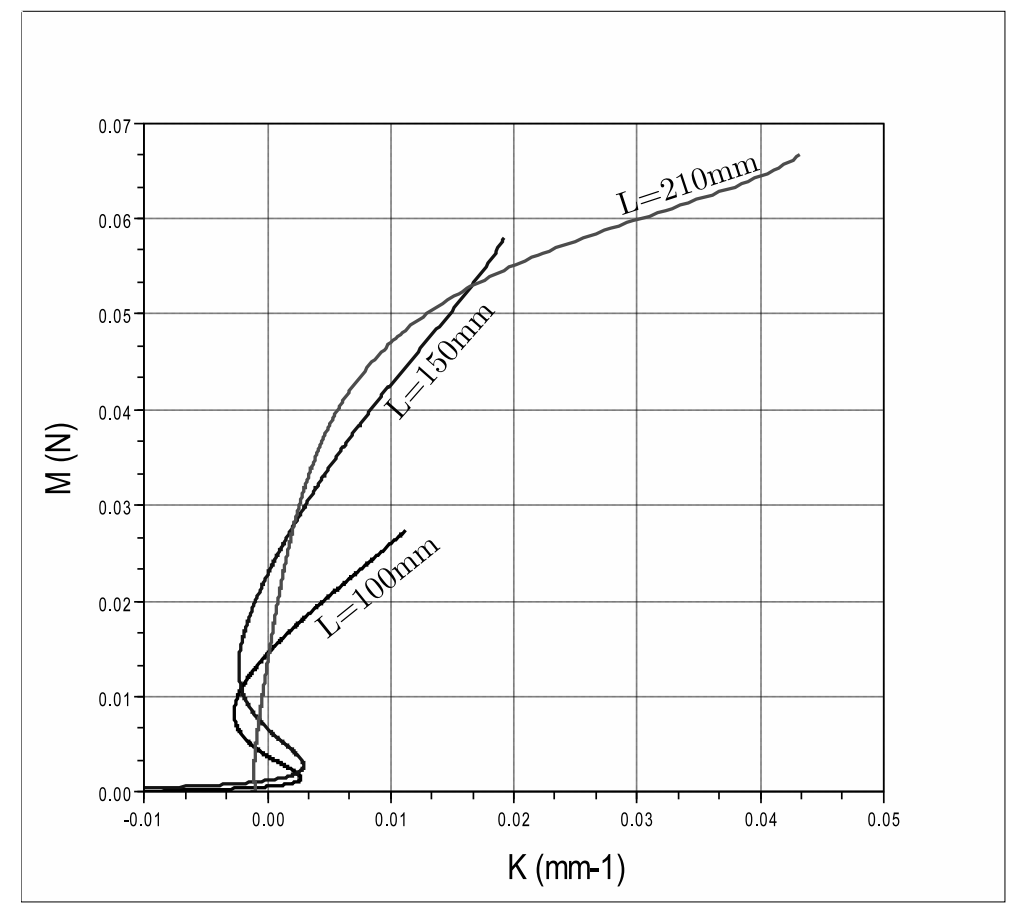

Fig. 13 Flexometer test on fabric A. Moment-curvature computed along the profiles for $\mathrm{L}=100 \mathrm{~mm}, \mathrm{~L}=150 \mathrm{~mm}$ and $\mathrm{L}=210 \mathrm{~mm}$. 


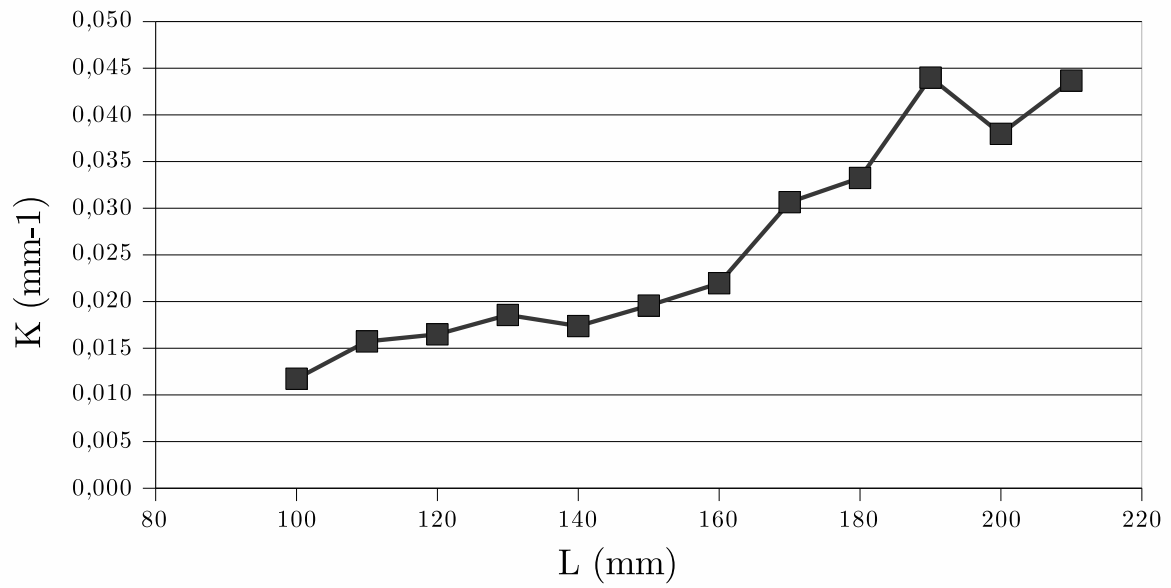

(a) Curvature vs Bending length

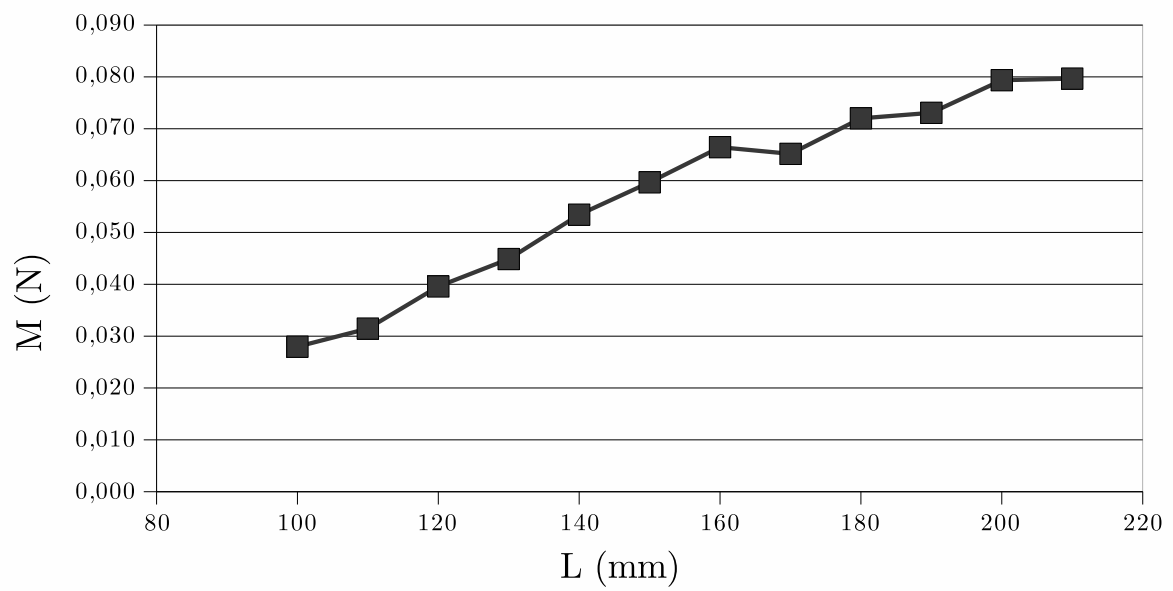

(b) Moment vs Bending length

Fig. 14 Flexometer test on fabric A. Curvature and moment computed at embedded point vs Bending length 


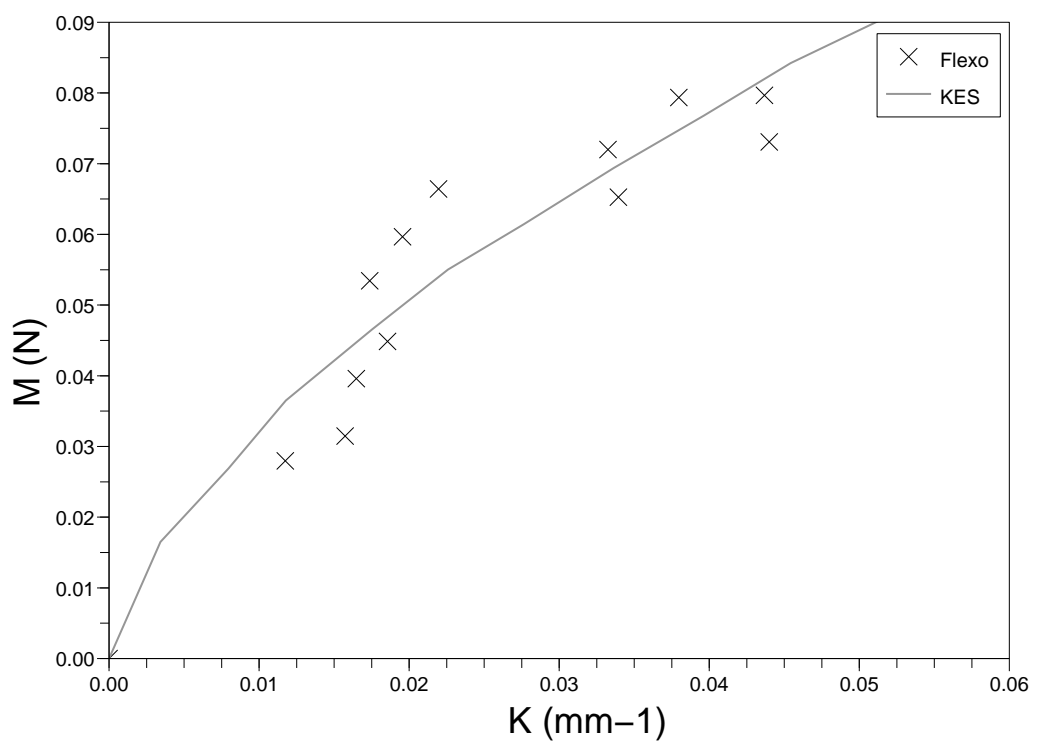

Fig. 15 Bending curve for fabric A - Comparison with Flexometer test and KES-FB2 


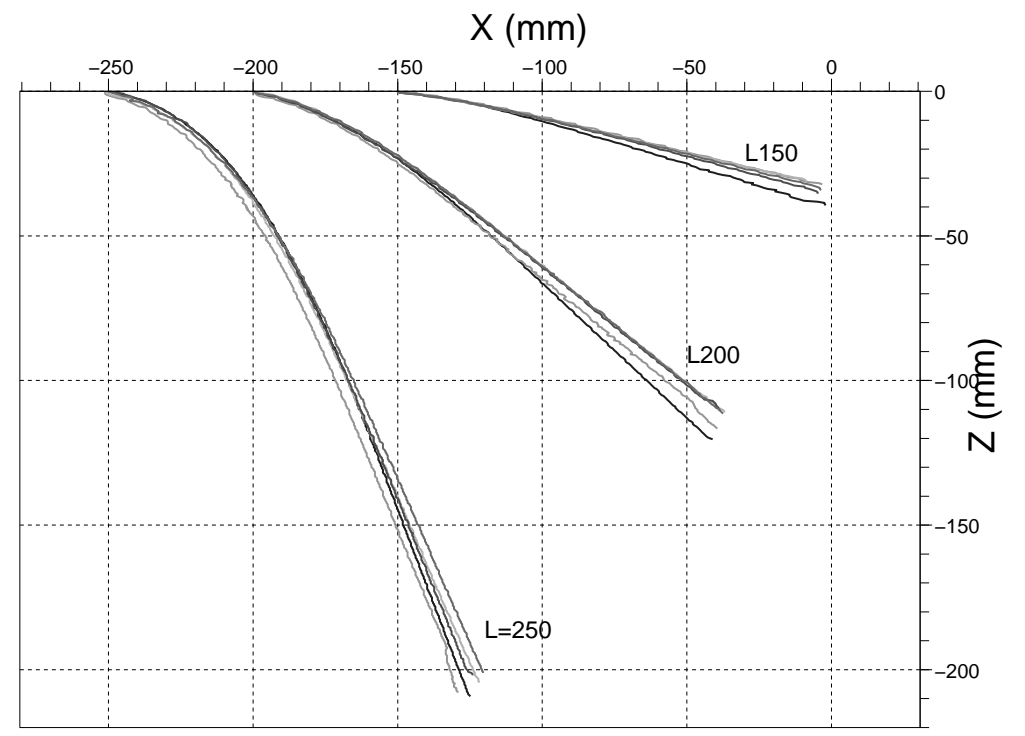

(a) Profiles

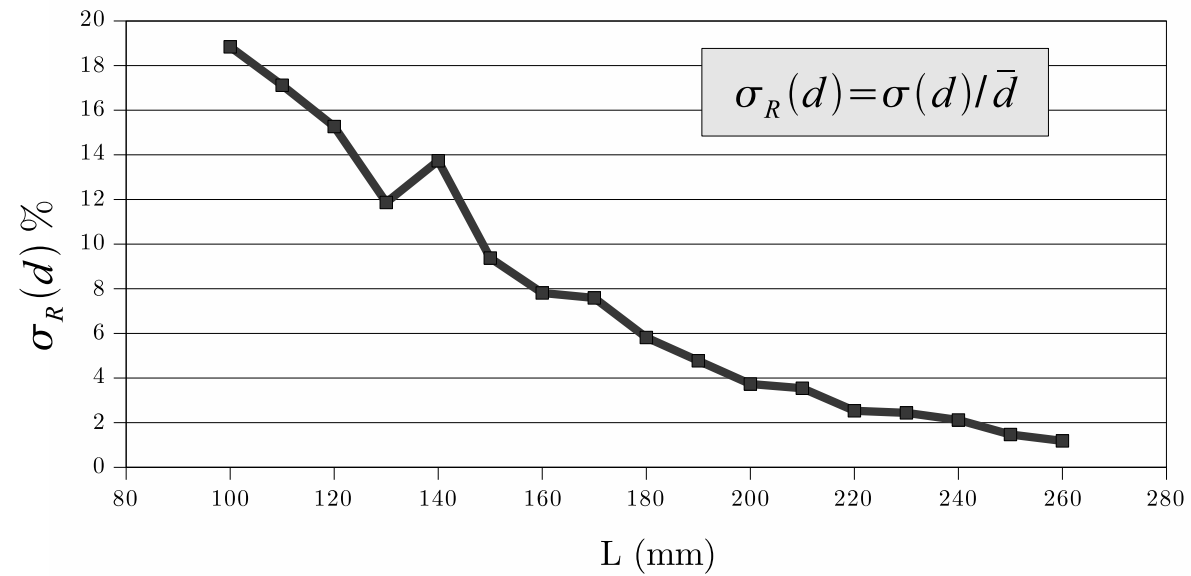

(b) Repeatability of maximal deflection $(\mathrm{d}=\mathrm{Z}$ co-ordinate of free edge $\mathrm{F}$ )

Fig. 16 Flexometer test on fabric B. Repeatability on the reinforcement for bending lengths $\mathrm{L}=150 \mathrm{~mm}, \mathrm{~L}=200 \mathrm{~mm}$ et $\mathrm{L}=250 \mathrm{~mm}$ 


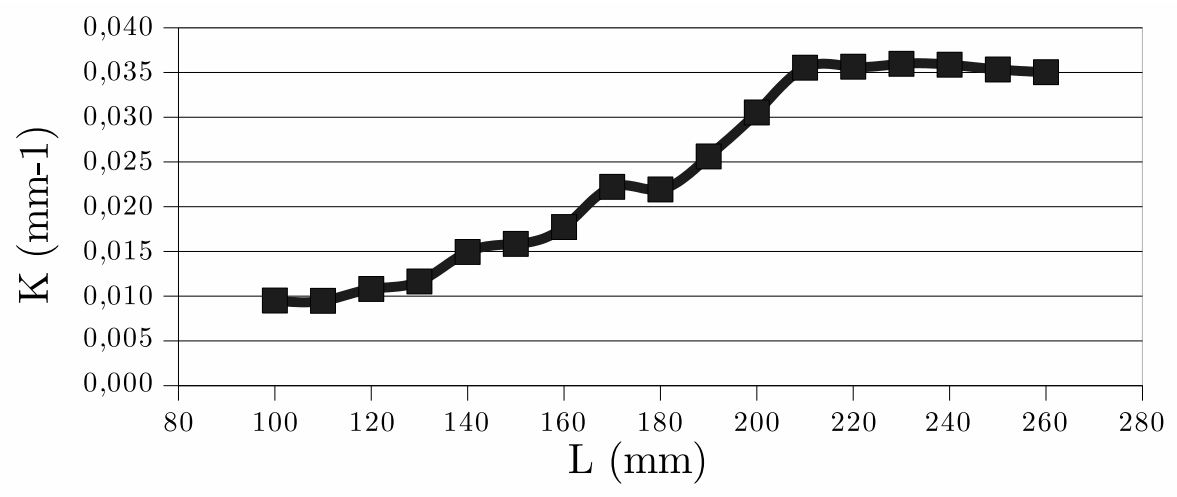

(a) Curvature vs Bending length

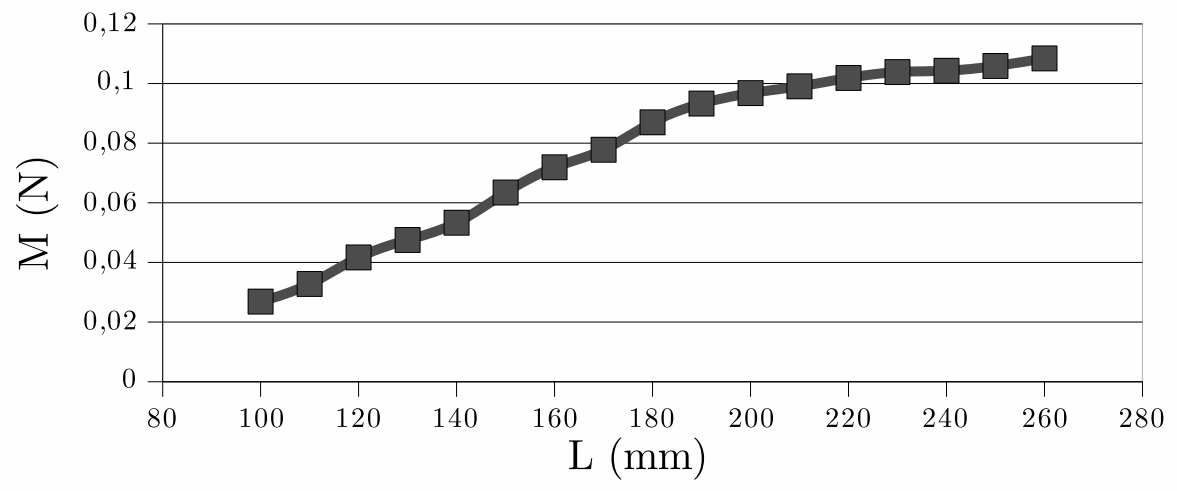

(b) Moment vs Bending length

Fig. 17 Flexometer test on fabric B. Curvature and moment computed at embedded point vs Bending length 


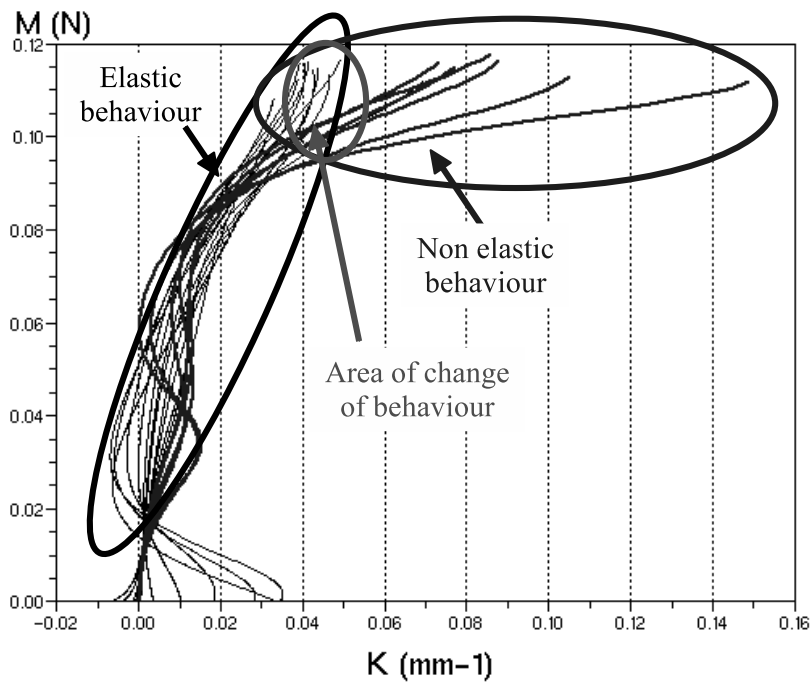

Fig. 18 Flexometer test on fabric B with added mass. Curvature and moment computed along profiles vs bending length.

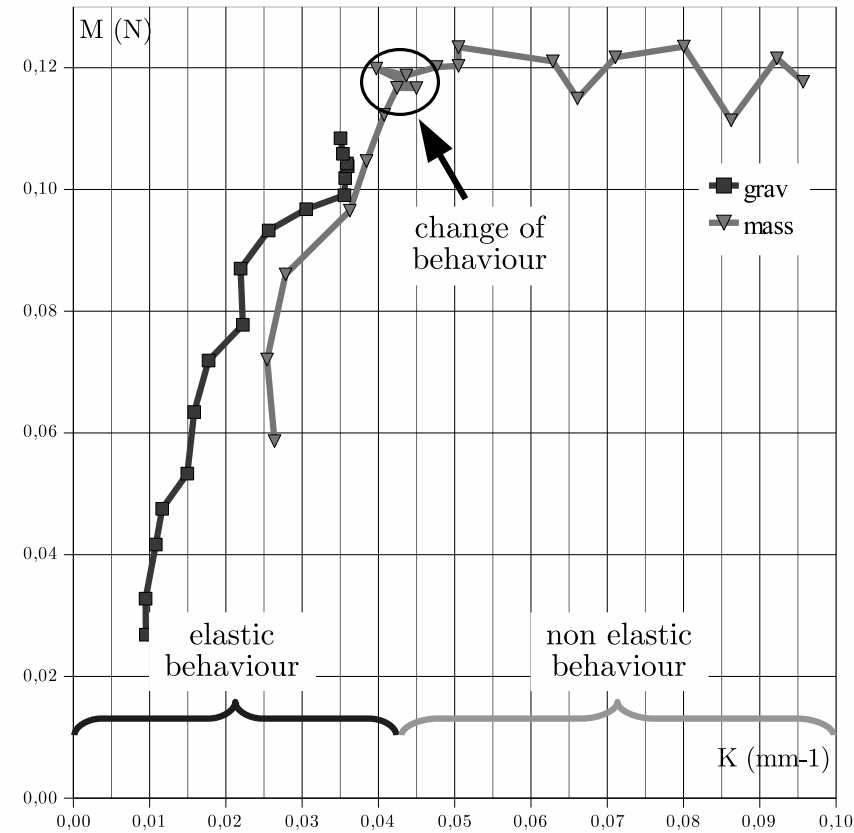

Fig. 19 Bending curve for fabric B under gravity and with added mass. 


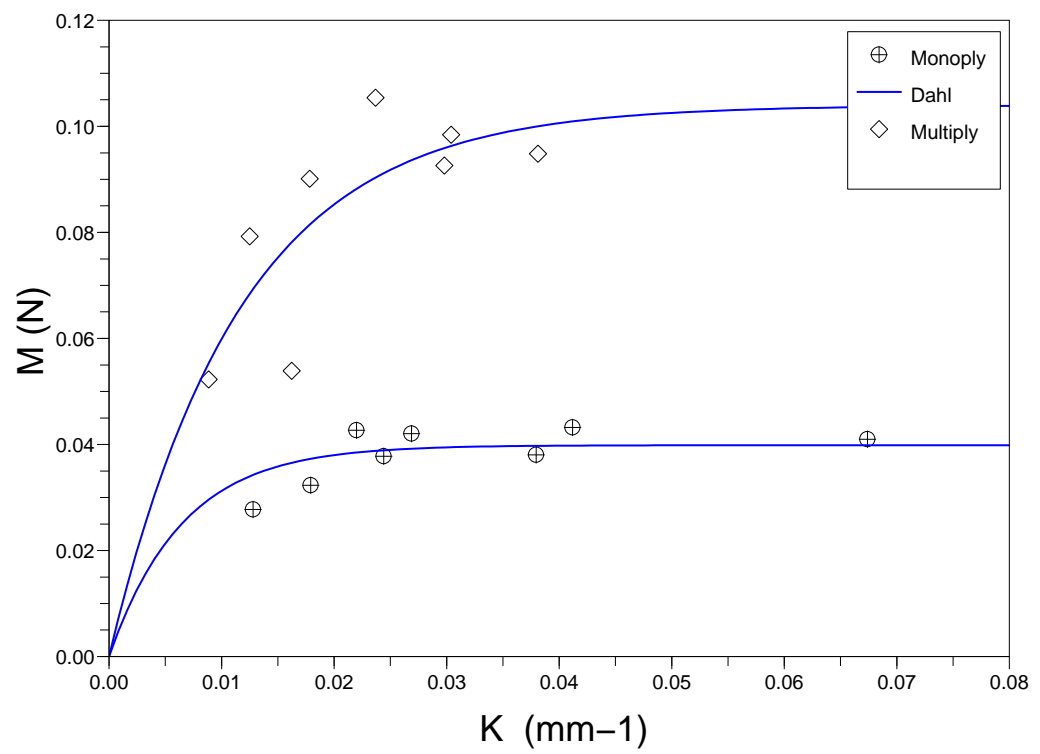

Fig. 20 Bending curve for fabric $\mathrm{C}(\mathrm{NCF})$ and fabric D (Multiply $\mathrm{NCF}$ ). 
503

1. Long, A.: Design and manufacture of textile composites. Woodhead Publishing Ltd (2005)

2. Rudd, C., Long, A., Kendall, K., Mangin, C.: Liquid Moulding Technologies. Woodhead Publishing (1997)

3. Potter, K.: The early history of the resin transfer moulding process for aerospace applications. Composites Part A: Applied Science and Manufacturing 30(5), 619-621 (1999)

4. Parnas, R.S.: Liquid composite molding. Hanser Gardner Publications (2000)

5. Maison, S., Thibout, C., Garrigues, C., Garcin, J., Payen, H., Sibois, H., Coiffer, C., Vautey, P.: Technical developments in thermoplastic composites fuselages. In: SAMPE journal, 5, pp. 33-39 (1998)

6. Soulat, D., Cheruet, A., Boisse, P.: Simulation of continuous fibre reinforced thermoplastic forming using a shell finite element with transverse stress. Computers and structures $\mathbf{8 4}$, 888-903 (2006)

7. Long, A., Rudd, C.D.: A simulation of reinforcement deformation during the production of preforms for liquid moulding processes. ARCHIVE: Proceedings of the Institution of Mechanical Engineers, Part B: Journal of Engineering Manufacture 1989-1996 (vols 203210) 208(42), 269-278 (1994)

8. Pillai, K., Advani, S.: The role of dual permeability of fiber preforms in resin transfer molding. In: Proceedings of the American Society for Composites Ninth Technical Conference (1994)

9. Rudd, C., Long, A., McGeehin, P., Cucinella, F., Bulmer, L.: Processing and mechanical properties of bi-directional preforms for liquid composite moulding. Composites Manufacturing 6(3-4), 211-219 (1995)

10. Advani, S., Bruschke, M., Parnas, R.: Flow and Rheology in Polymeric Composites Manufacturing, chap. 12 - Resin transfer molding. Elsevier Publishers (1994)

11. Rudd, C., Middleton, V., Owen, M., Long, A., McGeehin, P., Bulmer, L.: Modelling the processing and performance of preforms for liquid moulding processes. Composites Manufacturing 5(3), 177-186 (1994)

12. Laroche, D., Vu-Khanh, T.: Forming of woven fabric composites. Journal of Composite Materials 28(18), 1825-1839 (1994) 
13. Mark, C., Taylor, H.: The fitting of woven cloth to surfaces. Journal of Textile Institute (1956)

14. Van Der Weeën, F.: Algorithms for draping fabrics on doubly-curved surfaces. International Journal for Numerical Methods in Engineering 31(7), 1415-1426 (1991)

15. Cherouat, A., Borouchaki, H., Billoët, J.: Geometrical and mechanical draping of composite fabric. European Journal of Computational Mechanics (2005)

16. Boisse, P., Zouari, B., Gasser, A.: A mesoscopic approach for the simulation of woven fibre composite forming. Composites Science and Technology 65(3-4), 429-436 (2005)

17. Boisse, P., Zouari, B., Daniel, J.: Importance of in-plane shear rigidity in finite element analyses of woven fabric composite preforming. Composites Part A: Applied Science and Manufacturing 37, 2201-2212 (2006)

18. Zouari, B., Daniel, J., Boisse, P.: A woven reinforcement forming simulation method. influence of the shear stiffness. Computers \& Structures 84(5-6), 351-363 (2006)

19. Boisse, P., Hamila, N., Helenon, F., Hagege, B., Cao, J.: Different approaches for woven composite reinforcement forming simulation. International Journal of Material Forming $\mathbf{1}(1), 21-29(2008)$

20. Hamila, N., Boisse, P.: Simulations of textile composite reinforcement draping using a new semi-discrete three node finite element. Composites Part B: Engineering 39(6), 999-1010 (2008)

21. Launay, J., Hivet, G., Duong, A., Boisse, P.: Experimental analysis of the influence of tensions on in plane shear behaviour of woven composite reinforcements. Composites Science and Technology 68(2), 506-515 (2008)

22. Hamila, N.: Simulation de la mise en forme des renforts composites mono et multi plis. Ph.D. thesis, Institut National des Sciences Appliquées de Lyon (2007)

23. Wang, J., Long, A., Clifford, M., Lin, H.: Energy analysis of reinforcement deformations during viscous textile composite forming. In: E. Cueto, F. Chinesta (eds.) AIP Conference Proceedings, vol. 907, pp. 1098-1106. AIP (2007)

24. Yu, W., Zampaloni, M., Pourboghrat, F., Chung, K., Kang, T.: Analysis of flexible bending bahavior of woven preform using non-orthogonal constitutive equation. Composite Part A : Applied science and manufacturing 36 (6), 839-850 (2005) 
25. Peirce, F.: The geometry of cloth structure. The Journal of the Textile Institute 28, 45-96 (1937)

26. ASTM: Standard Test Method for Stiffness of Fabrics, chap. D1388-96(2002). American Society for Testing and Materials (2002)

27. ISO: Textiles glass -Woven fabrics - Determination of conventional flexural stifness - Fixed angle flexometer method, chap. iSO 4604:1978. ISO (1978)

28. Kawabata, S.: The standardization and analysis of hand evaluation. The Textile Machinery Society of Japan (1980)

29. Hivet, G., Boisse, P.: Consistent 3d geometrical model of fabric elementary cell. application to a meshing preprocessor for 3d finite element analysis. Finite element in analysis end design 42, 25-49 (2005)

30. Lomov, S., Belov, E., Bischoff, T., Ghosh, S., Truong Chi, T., Verpoest, I.: Carbon composites based on multiaxial multiply stitched preforms. part 1 . geometry of the preform. Composites Part A: Applied Science and Manufacturing 33(9), 1171-1183 (2002)

31. Boisse, P., Buet, K., Gasser, A., Launay, J.: Meso/macro-mechanical behaviour of textile reinforcements for thin composites. Composites Science and Technology 61(3), 395-401 (2001)

32. Boisse, P., Gasser, A., Hivet, G.: Analyses of fabric tensile behaviour: determination of the biaxial tension-strain surfaces and their use in forming simulations. Composites Part A: Applied Science and Manufacturing 32(10), 1395-1414 (2001)

33. Ghosh, T., Batr, S., Barke, R.: The bending behaviour of plain-woven fabrics. part i : A critical review. The Journal of the Textile Institute 81, 245-254 (1990)

34. Peirce, F.: The 'handle' of cloth as a measurable quantity. The Journal of the Textile Institute 21, 377-416 (1930)

35. Grosberg, P.: The mechanical properties of woven fabrics part ii : the bending of woven fabrics. Textile Research Journal 36 (3), 205-214 (1966)

36. Ngo Ngoc, C., BRUniAUX, P., J.M., C.: Modelling friction for yarn/fabric simulation application to bending hysteresis. In: Proceedings 14th European Simulation Symposium $(2002)$

37. Lahey, J.T., Heppler, G.R.: Mechanical modeling of fabrics in bending. ASME (2004) 
38. Grosberg, P., Kedia, S.: The mechanical properties of woven fabrics part i : the initial load extension modulus of woven fabrics. Textile Research Journal 36 (1), 71-79 (1966)

39. Clapp, T., Peng, H., Gosh, T., Eischen, J.: Indirect measurement of the moment-curvature relationship for fabrics. Textile Research Journal 60(9), 525-533 (1990)

40. Lomov, S., Boisse, P., Deluycker, E., Morestin, F., Vanclooster, K., Vandepitte, D., Verpoest, I., Willems, A.: Full-field strain measurements in textile deformability studies. Composites Part A: Applied Science and Manufacturing 39(8), 1232-1244 (2008)

41. Bailey, D.: Pixel calibration techniques. In: New zealand Image and Vision Computing 95 Workshop, pp. 37-42 (1995)

42. Bailey, D.: A rank based edge enhancement filter. In: New Zealand Image Processing Workshop, pp. 42-47 (1990)

43. de Bilbao, E., Soulat, D., Hivet, G., Launay, J., Gasser, A.: Bending test of composite reinforcements. In: ESAFORM 2008 (2008)

44. Dahl, P.: Solid friction damping of mechanical vibrations. AIAA Journal 14(12), 1675$1682(1976)$

45. Prodromou, A.G., Chen, J.: On the relationship between shear angle and wrinkling of textile composite preforms. Composites Part A: Applied Science and Manufacturing 28(5), 491-503 (1997) 